\section{Registrando a história da educação escolar da Comunidade Indígena Ñandeva-Guarani da Reserva Porto Lindo no município de Japorã, $\mathbf{M S}^{\mathbf{1}}$ Register of the history of education in the Indigenous Community of Ñandeva- -Guarani from the Reservation in Porto Lindo in Japorã municipality, MS}

\author{
Cristiane Beatriz Dahmer Couto²
}

DOI: http://dx.doi.org/10.20435/tellus.v0i31.412

Resumo: O presente texto relata o processo histórico da educação escolar indígena na comunidade Nandeva-Guarani, localizada na Reserva Porto Lindo, município de Japorã, Mato Grosso do Sul. A apresentação dos resultados tem início com uma retrospectiva histórica da comunidade indígena guarani no estado do Mato Grosso do Sul, do século XVI ao XXI, passando depois a pormenorizar os acontecimentos diretamente vinculados à criação da escola localizada na Reserva, foco deste estudo. A forma como se inicia a implantação da escola nessa comunidade, tendo como referência os dados documentais, os depoimentos recolhidos, e as práticas que ali vêm sendo efetivadas permitiram identifi car alguns dos problemas ligados tanto à questão da educação indígena, em geral, quanto aos problemas específi cos da comunidade enfoca.

Palavras-chave: educação escolar indígena; Nandeva-Guarani; Mato Grosso do Sul.

Abstract: The present study aims the accounting of the historical process of formal indigenous education in the Nandeva-Guarani community of the Porto Lindo Reserve, in the municipality of Japorã, Mato Grosso do Sul. The results introduction starts with a historical

\footnotetext{
${ }^{1}$ Este artigo é extraído de um dos capítulos da dissertação de mestrado denominada "História da implantação da educação escolar na Comunidade Indígena Nandeva-Guarani da Reserva Porto Lindo no Município de Japorã no Estado de Mato Grosso do Sul, Brasil".

${ }^{2}$ Universidade Estadual de Mato Grosso do Sul, Mundo Novo, Mato Grosso do Sul, Brasil.
}

Sobre a autora:

Grupo de Estudos em Ciências Ambientais e Educação (GEAMBE), Universidade Estadual de Mato Grosso do Sul, Mundo Novo, E-mail: dahmercouto@hotmail 
retrospective of the Guarani indigenous community from the state of Mato Grosso do Sul from the 16th up to the 21st centuries. Posteriorly, we detailed the events strictly bonded to the implementation of a school placed in the indigenous reserve, which is the focus of this study. The way the school was created in this community, based on the documental data, interviews, and the teaching practices, enabled the identification of some of the problems related to indigenous education, as well as specific problems of the community in question.

Key words: indigenous education; Nandeva-Guarani; Mato Grosso do Sul.

\section{INTRODUÇÃO}

No Brasil há 305 diferentes sociedades indígenas que somam cerca de 900 mil pessoas, falantes de 274 línguas distintas. Os índios vivem nos mais diversos pontos do território brasileiro e representam, em termos demográficos, um pequeno percentual da população brasileira. Todavia são exemplos concretos e significativos da grande diversidade cultural existente no País (IBGE, 2010).

O Estado do Mato Grosso do Sul (MS) tem a segunda maior população indígena do país, com cerca de 70 mil índios pertencentes a diferentes etnias, tais como Guarany ${ }^{3}$ [Kaiwá e Ñandéva], Kadiwéu, Terena, Guató, Ofayé e Atikum. Esses indígenas expressam-se em diferentes línguas, tais como Guarani, Guaná, Terena, entre outras (parafraseando MARTINS, 2002, p. 83-85).

Partindo do pressuposto que o estado do MS possui a segunda maior população indígena do Brasil e que, no município de Japorã na fronteira com o Paraguai, 49,4\% da população é indígena - situação que coloca o município com maior número de índios em relação à população do Estado - poder-se-ia supor que os não índios tivessem um maior esclarecimento a respeito desse povo e sua cultura, mas não é isso que se verifica: índios e não índios estão territorialmente ligados, mas culturalmente distantes.

Os não índios, na maioria das vezes, consideram os índios preguiçosos, incapazes, bêbados e totalmente inúteis, e crianças não índias, muitas vezes, crescem ouvindo esse discurso. Quando essas crianças chegam à escola, muitas vezes acabam ouvindo o mesmo discurso nas aulas de história, confirmando que os não índios, mesmo em vizinhança próxima dos índios, não os conhecem. Os livros didáticos "ensinam" que índio caça, pesca e mora em uma oca. A esse respeito, cabe citar Fleuri (2002, p. 449):

\footnotetext{
${ }^{3}$ Os Guarani, em Mato Grosso do Sul, estão representados pelas populações Kaiowá e Nandeva, sendo que esta se autorreconhece e é reconhecida pela denominação guarani, portanto, será tratada dessa forma (VIETTA, 2003, p. 132).
} 
A luta contra os estereótipos e os processos discriminatórios, assim como a defesa da igualdade de oportunidades e o respeito às diferenças não é um movimento simples, pois os mesmos argumentos desenvolvidos para defender relações mais justas, dependendo do contexto e do jogo político em que se inserem, podem ser ressignificadas para legitimar processos de sujeição e exclusão.

A Constituição Federal de 1988, em seu Artigo 231, diz que: "são reconhecidos aos índios sua organização social, costumes, línguas, crenças e tradições, e os direitos originários sobre as terras que tradicionalmente ocupam, competindo à União demarcá-las, proteger e fazer respeitar todos os seus bens". Consequentemente, a Lei de Diretrizes e Bases (LDB/96), em seus artigos 78 e 79, obriga os sistemas de ensino a desenvolver currículos e programas específicos e materiais didáticos diferenciados, dando à população indígena o direito de manter-se como tal e, ao mesmo tempo, ter educação escolar diferenciada, intercultural e bilíngue.

Como a lei garante aos povos indígenas o direito de manterem sua cultura $^{4}$, sua tradição e sua língua, por que a escola, assim como os projetos e programas existentes neste contexto, insistem em impor uma mudança cultural aos povos indígenas? A partir de quais informações e diagnósticos essas decisões foram tomadas? Será que foi realizada uma investigação com esse povo a respeito de suas aspirações ou de seu processo de inserção na sociedade dos não índios, com relação à perspectiva de futuro ou mudança de vida? E a língua materna, vem sendo respeitada? E o direito a ela? E o indígena, o que pensa a respeito de manter ou não a língua materna? Como esse povo vê a escola? O que é educação escolar para eles?

Para se compreender a Educação Escolar Indígena, é preciso conhecer o contexto histórico no qual está inserida. Isto é justificado através das palavras de Brandão (2004 p. 18-19), que diz:

Sob regime tribal, a característica essencial da educação reside no fato de ser difusa e administrada indistintamente por todos os elementos do clã. Não há mestres determinados, nem inspetores especiais para a formação da juventude: esses papéis são desempenhados por todos os anciãos e pelo conjunto das gerações anteriores.

O ponto de partida para a discussão e análise da educação escolar indígena é situar seu processo histórico. Há duas fontes de dados - documental e

\footnotetext{
${ }^{4}$ Cultura é entendida como um sistema de significados e símbolos; o comportamento seriam as ações dentro de uma determinada cultura e a cultura material seria representada pelos produtos tangíveis do comportamento, incluindo, vestígios faunísticos e botânicos (LANDA, 2005, p. 40). Cultura é o dispositivo pro meio do qual as sociedades vão se organizando e se transformando. A cultura não é o ingrediente, mas o recipiente "a panela", aonde o povo vai "beber o caldo da cultura" (AZEVEDO, 1999 apud NASCIMENTO, 2004, p. 46).
} 
oral - utilizadas nos estudos de história indígena no país; são os documentos (cartas, diários de navegações), grafados a partir de 1500 pelos colonizadores (ou os descendentes), viajantes e missionários, e tratam de reconstituição de fatos presenciados ou vivenciados com essa população.

Para atingir os objetivos, foram utilizadas como fontes de dados os documentos e depoimentos. Com relação aos documentos, apoiamo-nos, basicamente, em Magalhães (1999), que aponta a pesquisa documental composta por dois conjuntos de documentos: Histórias Anteriores e Arquivo. O primeiro é composto por livros, artigos em periódicos, dissertações e teses referentes ao campo de estudo. O segundo refere-se ao conjunto de documentos internos da instituição escolar, tais como: projeto de implantação das escolas, documentos legais relativos ao processo (decreto, resoluções, diário oficial, ata de resultados finais), censo escolar e regimento interno.

No caso das histórias anteriores, foi consultado o material referente a outras comunidades indígenas, pois, a respeito dessa comunidade e específico, não existem quaisquer trabalhos no campo educacional, apenas uma tese de doutorado, no campo da arqueologia, que subsidiou esta pesquisa.

No arquivo, encontramos dificuldades, pois a escola existe há mais de trinta anos, e nunca houve uma preocupação por parte de seus responsáveis em organizar sua documentação. Os documentos não são informatizados e, muitos deles, estão em arquivo morto em várias repartições, e pareceu haver pouca disposição dos membros da comunidade escolar (administrativo) para a localização das fontes - muitas vezes pareceu haver intencionalidade em dificultar o acesso aos documentos.

Utilizou-se, ainda, a História Oral como metodologia de pesquisa, por avaliarmos ser esta a melhor forma de compreender esse processo. Para ampliar a compreensão de História Oral, recorremos a Meihy (1996):

História oral é um conjunto de procedimentos que se iniciam com a elaboração de um projeto e continuam com a definição de um grupo de pessoas (ou colônia) a serem entrevistados, com o planejamento da condução das gravações, com a autorização para o uso, arquivamento e, sempre que possível, com a publicação dos resultados que devem, em primeiro lugar, voltar ao grupo que gerou as entrevistas. (MEIHY, 1996, p. 15).

Meihy (1996) classifica a história oral em três modalidades: história oral de vida; história oral temática; e tradição oral.

História Oral de Vida - quando está em estudo o percurso de vida de uma pessoa, História Oral Temática - quando as entrevistas focalizam uma situação em que os sujeitos estiveram envolvidos e sobre a qual tem informações, Tradição Oral - quando a pesquisa procura 
recolher informações que, sendo advindas de um passado longínquo, permanecem transmitidas oralmente, de geração a geração. (ABBUD, 2003, p. 26).

Este trabalho pode ser categorizado como História Oral Temática, considerando que o foco dos depoimentos é o processo histórico de instalação e funcionamento da escola junto aos Nandeva-Guarani da reserva Porto Lindo. A metodologia adotada neste estudo envolve sua autora em duplo papel: o de pesquisadora e de sujeito informante. $O$ fato de ser pesquisadora e também protagonista, professora da escola Polo José de Alencar amplia a possibilidade de diálogo, condição essencial para o trabalho em história oral.

Para a escolha dos colaboradores da pesquisa, ou seja, daqueles sujeitos que participariam do processo e teriam condições de informar sobre ele, foi necessário, no primeiro momento, definir a colônia, formando a rede a partir do colaborador ponto zero, que baliza a seleção dos demais entrevistados.

Para melhor compreender o que é colônia, tomamos a definição de Meihy (1996): colônia é o conjunto de pessoas que, em sua trajetória, compartilharam uma experiência. "A colônia é sempre a espécie, do qual a rede é o gênero". No caso desta pesquisa, a colônia foi formada por professores, alunos, funcionários de nível administrativo e membros da sociedade.

A partir do momento em que se define a colônia, é possível a formação da rede, uma subdivisão da colônia a partir do estabelecimento de parâmetros para decidir quem entrevistar. Como não se conhecia toda a comunidade que seria pesquisada, foi preciso delimitar o ponto zero, um depoente que conhecesse a comunidade e que pudesse indicar alguns caminhos a percorrer.

Para este estudo, a professora Beatriz dos Santos Landa, doutora em arqueologia, aceitou ser a colaboradora ponto zero. A professora foi a pessoa mais indicada para fornecer as informações necessárias. Em sua tese de doutorado, 2005, “Os Ñandeva/Guarani e o uso do espaço na terra indígena Porto Lindo/Jacarey, Município de Japorã, MS", trabalhou junto à comunidade, conhecendo-a e sendo por ela conhecida. Realizada a entrevista com a professora, obtivemos a indicação dos componentes da rede.

A professora Beatriz indicou os seguintes colaboradores para formar a rede: O Reverendo Rubens Francisco Carneiro e o Reverendo Benedito Troques, que foram os primeiros missionários a trabalhar com a comunidade; os professores indígenas Valdomiro Ortiz e Venâncio Cáceres, que acompanharam o processo histórico como personagens deste; a professora Lídia Rocha Javolski, uma educadora não índia que trabalha na comunidade há vinte anos e, por último, o ex-secretário de educação municipal, o professor Paulo 
Franjote, que foi o tutor dos indígenas na primeira turma do projeto Ara Verá ${ }^{5}$ Assim então ficou definida a rede de entrevistas para esta pesquisa; os dados referentes aos entrevistados encontram-se no Anexo 1.

\section{A HISTÓRIA DA EDUCAÇÃO ESCOLAR INDÍGENA ÑANDEVA- -GUARANI}

No dia 14 de novembro de 1928, o governo de Mato Grosso (hoje Mato Grosso do Sul, em virtude de desmembramento ocorrido em 1977), através do Decreto n. 835, criou a Terra Indígena Porto Lindo.

À época, a Reserva Porto Lindo era habitada, de forma marcante, pelos Nandeva que, aos poucos, foram sendo empurrados para dentro da Reserva, pois a Matte Laranjeira ${ }^{6}$, os produtores rurais, os fazendeiros de gado e o processo político de criação de municípios foram encurralando-os. Iniciou-se o processo de extração de madeiras e assoreamento dos rios, dificultando a pesca e extinguindo a caça, deixando sem alimentos os indígenas. Mas a ironia e o absurdo maior de toda essa situação foi o fato de que os indígenas atuaram como mão de obra em todas as etapas que culminaram na espoliação de seus territórios (BRAND, 1997; MELIA, 2004; GRASSI, 2004 apud LANDA, 2005, p. 73).

Em depoimento oral, o reverendo Rubens nos diz que, no ano de 1960, quando chegou à região de Iguatemi, especificamente na Reserva Porto Lindo, havia ali apenas 80 índios, mas, anos depois, já se estimava a população da Reserva em 1500 indígenas. Onde estavam esses índios e por que vieram para a Reserva? O revendo nos apresenta a seguinte hipótese:

[...] quando chegamos lá havia apenas oitenta pessoas, era um grupo de oitenta pessoas, quando eu vim para Dourados e, em 1976, a aldeia já contava com um número aproximadamente de mil e quinhentos indígenas, que fenômeno foi este? Os indígenas viviam espalhados por

\footnotetext{
${ }^{5}$ O Curso Normal em Nível Médio de Formação de Professores Guarani/Kaiowá - Projeto "Ára Verá" (espaço-tempo iluminado) - consiste em ação cujo objetivo geral é formar professores indígenas Guarani/Kaiowá em nível médio, com habilitação para a educação nas comunidades indígenas, educação nas séries iniciais do ensino fundamental e educação infantil. Seu funcionamento foi autorizado por meio da Deliberação/CEE/MS n. 6284 de 20 de julho de 2001(ROSSATO, 1999).

${ }^{6}$ A Cia Matte L S laranjeira instala-se em todo o território ocupado pelos Kaiowá e Guarani, em Mato Grosso do Sul, após a Guerra do Paraguai, tendo em vista a exploração dos ervais nativos, abundantes em toda a região. Antes disso, em 1767, o Governo Português instalara, às margens do Rio Iguatemi, em pleno território Kaiowá, o Forte Iguatemi (Povoação e Praça de Armas Nossa Senhora dos Prazeres e São Francisco de Paula do Iguatemi), de curta duração (BRAND, 2003).
} 
fazendas trabalhando etc. Quando nós chegamos lá e começamos a dar a eles alguma assistência educacional, assistência de saúde, assistência de sentar com eles para conviver com eles, conversar com eles e orientar o trabalho que eles tinham que fazer na sua própria Reserva, esta notícia correu e o resultado foi que os indígenas começaram a retornar à sua aldeia e começaram a ter alguma assistência e algum cuidado por alguém que poderia fazer alguma coisa por eles [sic]. (Reverendo Rubens Carneiro, Entrevista, 2006).

Nos últimos anos, a população da Reserva Porto Lindo teve um aumento considerável em sua população - de 2.300 pessoas, no ano de 1999, para 3.661 no ano de 2004 e em2010, estimava-se 4.000 indígenas (IBGE, 2010).

No município de Japorã, fronteira com o Paraguai, 49,4\% da população é indígena. Situação que o coloca com maior o número de índios em relação à população no estado de Mato Grosso do Sul (IBGE, 2010).

“Uma das explicações dada pelos indígenas é de que um grande contingente de 'paraguaios ${ }^{7}$ veio para o local, estimulado pelo atendimento de saúde diário, pela oferta de cesta básica dentro da área, e de condições de vida melhores do que as oferecidas pelo país" (LANDA, 2005, p. 77). Outro argumento sobre o aumento populacional são os indígenas de outras localidades que acabaram vindo para Porto Lindo por diversos motivos como casamento, disputas internas e religiosidade, entre outros.

A documentação da FUNAI ${ }^{8}$ denomina de "Porto Lindo" esta terra indígena localizada à margem direita do rio Iguatemi, atualmente inserida no município de Japorã, ao sul do estado. Os Ñandeva/Guarani denominam esta área por Jacarey como uma referência ao córrego de mesmo nome que delimita a porção sul da mesma. A uma distância de apenas $5 \mathrm{~km}$, há um distrito do município com este mesmo nome, cuja população é composta por aproximadamente 800 pessoas. Os adolescentes, a partir da $5^{\mathrm{a}}$ série do Ensino Fundamental, no período diurno, assim como adolescentes e adultos que reiniciaram seus estudos frequentam as salas de aula na escola local no período noturno. Foram implantadas a $5^{\mathrm{a}}$ e $6^{\mathrm{a}}$ séries no ano de 2004, sendo que os alunos e alunas podem optar por continuar estudando na área ou deslocar-se até Jacareí. (LANDA, 2005, p. 78).

\footnotetext{
${ }^{7}$ Lembrando que estes paraguaios são índios Guarani. Em geral os que se deslocam tem algum parente ou conhecido na Porto Lindo, e dificilmente alguma família entra na área sem relacionar-se anteriormente com algum morador, até para garantir que tenha abrigo enquanto aguarda para construir casa local destinado pelo capitão (LANDA, 2005, p. 75).

${ }^{8}$ Em 1967 foi extinto o Serviço de Proteção ao Índio (SPI), que havia sido criado em 1910 com o objetivo de proteger os índios das crueldades e violências da expansão nacional e integrá-los ao conjunto da sociedade brasileira. Além de estar submerso em corrupção, este órgão não servia aos objetivos do regime militar. Em seu lugar, foi criada a fundação Nacional do Índio (FUNAI), cujo quadro dirigente expressa a militarização da questão indígena, por ser composta de elementos oriundos dos órgãos de segurança e informação. As comunidades indígenas e suas lideranças passam a viver sob forte controle (CARVALHO, 2002, p. 142).
} 
Hoje, essa comunidade indígena está cercada por assentamentos e fazendas cujos proprietários se dedicam à criação de gado e ao cultivo agrícola de milho, soja, algodão e mandioca. Além destes, existe o tráfego de carros e caminhões na estrada estadual MS-386, ao lado da Reserva, que influencia na vida da comunidade.

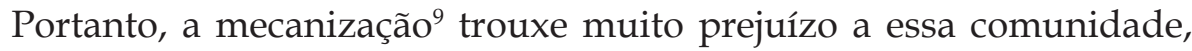
pois a vegetação foi alterada, com extinção de caça e coletas que antes eram praticadas. Por isso, os indígenas continuam sendo mão de obra dos não índios, como constatou Landa (2005): “alguns proprietários servem-se da mão de obra indígena em algumas tarefas, outros não permitem a entrada destes nas suas terras, impedindo-os de coletar madeira para fogo, e existem aqueles que mantêm um relacionamento bastante amigável com eles".

O foco deste trabalho é saber como ocorreu o processo histórico escolar da comunidade Ñandeva/Guarani da Reserva Porto Lindo - por isto se efetivou este "passeio" sobre o povo guarani no estado de Mato Grosso do Sul. Acreditamos que a educação e a história estão envolvidas em um movimento dialético no qual uma depende da outra e ambas se constituem simultânea e dependentemente.

\subsection{No tempo e no espaço: a escola}

Os projetos de escolas para os índios são tão antigos quanto o processo de colonização no Brasil. "O colonialismo, a educação para os índios e o proselitismo religioso são práticas que têm, no Brasil, a mesma origem e mais ou menos a mesma idade" (SILVA; AZEVEDO, 2004, p. 149).

Os missionários foram os primeiros encarregados de sistematizar a educação entre os povos indígenas e tinham claro que, para que esse processo escolar tivesse sucesso, seria necessário, primeiro, estudar a língua indígena. Com esta estratégia, souberam aliar métodos de controle político a algum tipo de atividade escolar "civilizatória".

Com a vinda da República, o quadro da educação indígena não muda, pois a educação escolar continua a cargo das missões religiosas. Segundo Silva e Azevedo (2004, p. 150):

${ }^{9}$ A data da destruição das aldeias está relacionada diretamente ao avanço do desmatamento e
corresponde à implantação das fazendas. A destruição de parte delas foi anterior a década de 1950.
Estão nesta situação as aldeias localizadas na área abrangida pela CAND. Porém, a maior parte
das aldeias teve sua destruição concluída durante as décadas de 1950 e 1960 [...]. Cabe ressaltar
que, em muitos casos, o esparramo nem sempre foi resultado de uma ação direta de expulsão, mas
de um progressivo processo de inviabilização da permanência dos índios naquele local. Este fato
torna, por vezes, difícil o estabelecimento de referências cronológicas (BRAND, 1997, p. 130-1). 
O panorama da educação escolar indígena foi um só, marcado pelas palavras de ordem 'catequizar', 'civilizar' e 'integrar' em uma cápsula, pela negação da diferença. E não se pense que este paradigma é coisa do passado. Grande parte das escolas indígenas hoje em nosso país tem como tarefa principal a transformação do 'outro' em algo assim como um 'similar' que, por definição, é algo sempre inferior ao 'original'.

Hoje, uma educação escolar diferenciada e de qualidade, intercultural e bilíngue, é reivindicada por várias organizações indígenas, com base na Constituição Federal e na LDB, que lhes garantem educação diferenciada e de qualidade. Existem inúmeras escolas nas comunidades indígenas, nos moldes das escolas que os missionários implantaram, e não houve mudanças em seus currículos e seus métodos. Segundo o Referencial Curricular para Escolas Indígenas (RCNEI), o "cotidiano da maior parte dos povos indígenas no Brasil desenrola-se num contexto de tensão entre conhecimentos indígenas e ocidentais" (RCNEI, 1998).

Existem, atualmente, aproximadamente 1.591 escolas indígenas no Brasil. Todas oferecem o ensino fundamental (primeiro segmento) e algumas oferecem o segundo segmento, segundo RCNEI (1998). Ao lado delas, há muitas escolas não indígenas que atuam dentro das Reservas como escola para o índio, como é o caso da Escola Pólo Municipal de Educação Infantil e Ensino Fundamental José de Alencar ${ }^{10}$ e suas extensões.

Os documentos que integram o acervo dessa escola forneceram o ponto de partida para atingir os objetivos desta pesquisa. A partir deles, buscou-se elaborar uma trajetória histórica da Escola Polo Municipal de Educação Infantil e Ensino Fundamental José de Alencar, responsável pela educação escolar dos alunos índios da Reserva Porto Lindo.

\subsubsection{A escola polo hoje}

Fundada em 1977, a Escola Pólo Municipal de Educação Infantil e Ensino Fundamental José de Alencar está localizada no Distrito de Jacareí, a 18 quilômetros da sede do município de Japorã, nas proximidades de três assentamentos: Roseli Nunes, Indianópolis, Princesa do Sul e da Reserva Indígena Porto Lindo.

Três das extensões localizam-se dentro da Reserva Indígena Porto Lindo, e a quarta localiza-se na Missão Caiuá, ou simplesmente Missão, como é

\footnotetext{
${ }^{10}$ Muitas vezes designada simplesmente por Escola Pólo, representa a sede onde todos os documentos estão organizados, onde as matrículas são realizadas e onde a direção faz os encaminhamentos. As reuniões pedagógicas são realizadas na escola Pólo e na extensão Porto Lindo. Reuniões de interesse de todos sempre são realizadas na sede, na Escola Pólo, que possui quatro extensões, uma ao lado da Reserva e três dentro da Reserva.
} 
conhecida na região, localizada ao lado da Reserva, como pode ser visto no mapa, na figura 1.

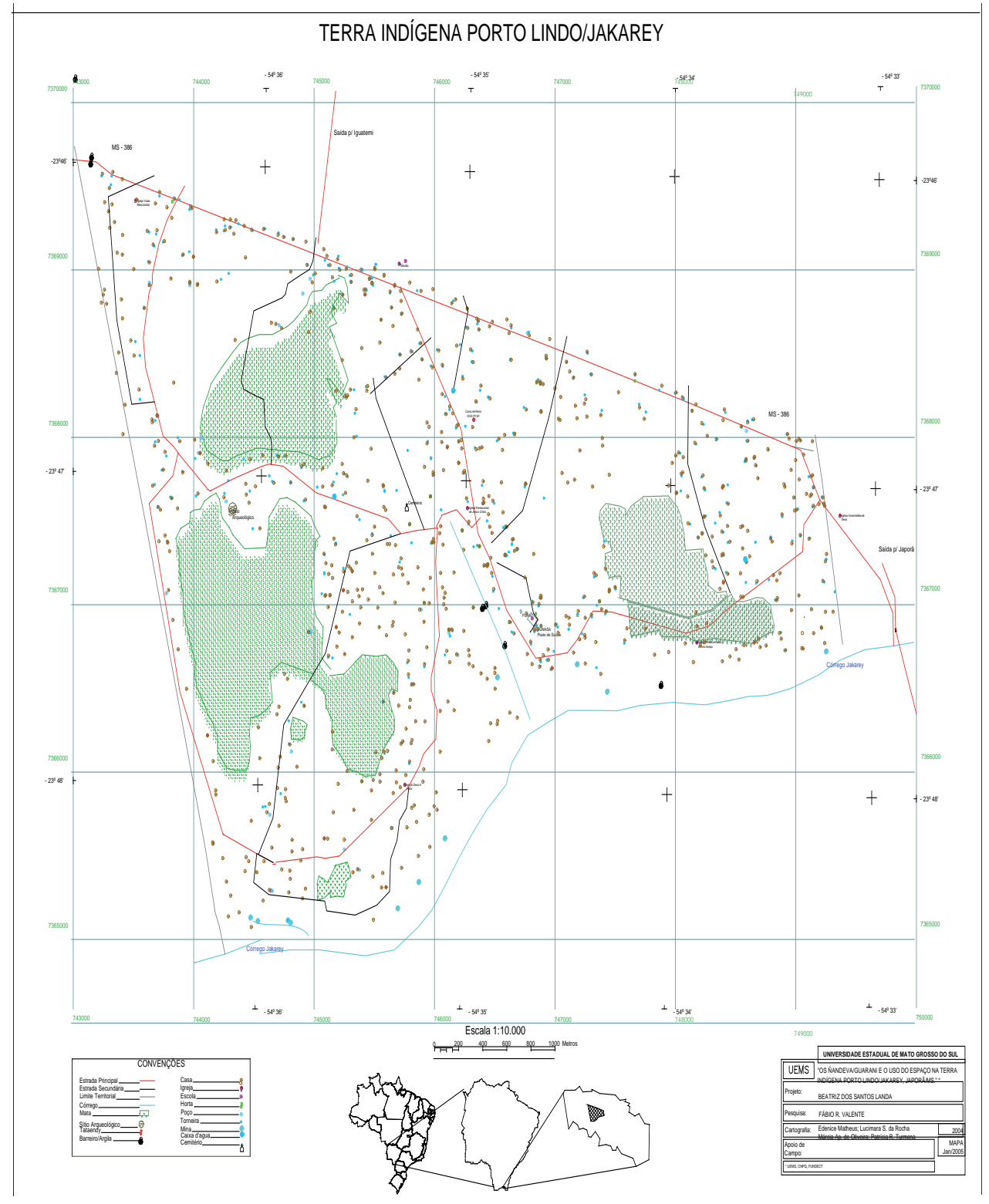

Figura 1 - Mapa da Reserva Porto Lindo. Fonte: LANDA, 2005.

A Unidade Escolar foi criada pela lei municipal número 028/77 com o nome de "Escola José de Alencar" e, naquela época, o estado mantinha escolas estaduais rurais, instituições pequenas, situadas na zona rural. Essas escolas 
eram então dependentes do executivo estadual; hoje, são de responsabilidade do município. Originalmente, funcionavam com salas multisseriadas.

Em 1994, as Escolas Estaduais Rurais foram unificadas administrativamente à Escola Municipal de $1^{\circ}$ grau "José de Alencar", ou seja, esta escola passa a abrigar todas as Escolas Rurais que integram a Rede Municipal de Ensino, determinando, assim, sua atuação como Escola Pólo, incumbida de operacionalizar a política municipal de ensino.

Na etapa da Educação Básica - Ensino Fundamental, a Escola Polo atende 1800 alunos, na faixa etária de 5 a 30 anos de idade, distribuídos em 31 turmas na Escola Polo e 35 turmas nas extensões. Nestas, é oferecido apenas o primeiro segmento do Ensino Fundamental, sendo que duas das extensões ainda utilizam o ensino multisseriado. Em 2005, a extensão Porto Lindo, que fica na sede da Reserva, começou a oferecer o segundo segmento, em implantação gradativa a partir da $5^{\mathrm{a}}$ série.

No ano de 2005, pela primeira vez, houve concurso público para professor no município de Japorã - até então eram todos contratados em regime de "contrato temporário". A pós o concurso, os professores efetivos não foram suficientes para completar o quadro, restando ainda muitas vagas em aberto, para as quais foram feitos "contratos temporários". É preciso ressaltar que, nesse quadro, muitos professores estão ministrando aulas em disciplinas para a qual não têm formação.

A Unidade Escolar possui prédio próprio doado pelo Instituto Nacional de Colonização e Reforma Agrária (INCRA), através de convênio com Prefeitura Municipal de Japorã, MS. A escola possui 11 salas de aula. Há dependências de uso específico para direção, coordenação, secretaria, sala de professores, biblioteca e cozinha. A Escola possui dois banheiros, uma quadra descoberta e um bebedouro com freezer.

Possui área coberta entre os pavilhões que dão acesso às salas de aula, coordenação, biblioteca cozinha e banheiro. O mobiliário existente e em uso, da secretaria, sala dos professores, da coordenação, da biblioteca e direção está em perfeito estado de conservação. Nas salas de aula, o mobiliário é composto por conjuntos de mesas e cadeiras individuais. A Escola possui materiais tecnológicos como: televisor, videocassete, retroprojetor, mimeógrafo, computador (para uso da secretaria), aparelho de som e filmadora.

Na biblioteca há livros de Literatura Infantil, Enciclopédia Ilustrada, Enciclopédia Barsa, Dicionários, Atlas Geográfico, Atlas de Anatomia eSaúde, livros de Eletrônica Básica, livros de Contos e Estórias, Dicionário de Inglês, Bíblia etc. Há também um acervo de fitas para vídeo abrangendo as áreas de 
conhecimento em Língua Portuguesa, Matemática, Ciências, Geografia, História, Educação Física, Educação Artística e Ensino Religioso, próprias para todas as séries do Ensino Fundamental.

O material de expediente em estoque, tal como sulfite, papel de diversas qualidades, estêncil e outros e o material escolar, tal como caderno, lápis e borracha, apresenta quantidade suficiente para o atendimento aos alunos e aos professores.

A área destinada à secretaria abriga mobiliário no qual se encontra arquivada toda a documentação escolar na forma de ativo (alunos, professores e funcionários em atividade) e, em outro espaço na mesma sala, estão arquivados todos os documentos na forma de passivo (de ex-alunos, ex-professores e ex-administrativos).

A escrituração escolar e a organização dos arquivos que asseguram a verificação da identidade de cada aluno, bem como a regularidade e autenticidade dos registros da vida escolar das extensões, na forma de ativo e passivo, estão arquivados na Secretaria de Educação em Japorã, onde há uma sala com dois funcionários administrativos que realizam todo o trabalho relacionado às extensões, tais como matrícula, transferência, controle de frequência dos alunos, organização dos arquivos e demais assuntos relacionados às extensões.

A Secretaria de Educação localiza-se a $18 \mathrm{~km}$ da reserva Porto Lindo. Se houver necessidade de algum documento de aluno que esteja arquivado lá, pode acontecer de passar dias até que ele esteja acessível. No início do ano letivo, muitas vezes, os alunos são colocados em salas trocadas e há demora em se corrigir a situação. Na sala em que a autora desta pesquisa leciona, já ocorreu de o nome de aluno estar trocado e levar dias para que se descobrisse o nome correto. Não há, no início do ano letivo, uma relação com nomes e data de nascimento correta, e os professores precisam perguntar aos alunos suas idades. Também acontece de o diário de classe chegar apenas no final do segundo bimestre.

A Escola Polo José de Alencar não possui Proposta Pedagógica, apenas um Regimento Escolar, com algumas adequações quanto a:

- Avaliação interna;

- Número mínimo e máximo de alunos portadores de necessidades especiais;

- Frequência do aluno que ingressa após o início do ano letivo;

- Rendimento do aluno que ingressa após o início do ano letivo;

- Incineração;

- Forma de arquivo e outros. 
A Unidade Escolar não possui projeto político pedagógico, não possui um currículo, uma filosofia, uma metodologia nem um sistema de avaliação direcionada. Cada professor utiliza como base os Parâmetros Curriculares Nacionais para a elaboração de seu plano de anual de atividades, selecionando assim os conteúdos para as disciplinas que ministram.

O corpo docente da sede José de Alencar é formado por 20 professores com contratos efetivos e 21 professores com contratados temporários.

Os gestores da escola Polo José de Alencar são o Secretário Municipal de Educação, o Diretor da escola, um Diretor Adjunto, oito Coordenadores (sendo quatro na Escola Polo e quatro nas extensões) e cinco Auxiliares de Secretaria (três atuando na Secretaria Municipal de Educação e dois na escola Polo).

A Escola Polo José de Alencar atende alunos indígenas e não indígenas desde a Educação Infantil até as séries finais do Ensino Fundamental. As extensões da Escola Polo José de Alencar são em número de quatro: Extensão Dr. Nelson Araújo, localizada na Missão Caiuá, $5 \mathrm{~km}$ ao norte da sede; Extensão Porto Lindo, localizada na sede da reserva de Porto Lindo; Extensão Afonso Pena, localizada $3 \mathrm{~km}$ a oeste da sede da reserva e Extensão Antônio Maria Coelho, $5 \mathrm{~km}$ a noroeste da sede da reserva. Na sequência, apresenta-se a caracterização de cada uma delas.

\subsubsection{Extensão Dr. Nelson de Araújo (Missão)}

Essa Unidade Escolar é uma extensão da Escola Polo José de Alencar e atende alunos da Reserva Indígena Porto Lindo. Localizada a cinco quilômetros da sede, escola Porto Lindo, oferece Educação Infantil e Ensino fundamental totalizando 248 estudantes.

A Escola possui cinco salas de aula e uma sala adaptada na antiga igreja, o mobiliário das salas de aula é composto por conjuntos de mesas e cadeiras individuais, suficientes para todos os alunos. As salas de aula são bem arejadas, as janelas são grandes, há boa ventilação e iluminação tanto natural como artificial. A pintura das paredes está desgastada e as instalações elétricas, hidráulicas e sanitárias estão em estado regular, bem como as condições de limpeza e higiene. Os banheiros são insuficientes para o turno matutino, pois há apenas dois vasos sanitários e lavatórios separados por sexo, um para cada 79 alunos matriculados. Há uma ampla área de lazer com gramado, para prática de Educação Física.

A formação do corpo docente dessa extensão é composta por 10 professores, todos com contratos temporários, sendo 08 não índios e apenas dois indígenas. 


\subsubsection{Extensão Porto Lindo}

A extensão funciona na sede da Reserva Indígena Porto Lindo e é constituída por dois blocos construídos em alvenaria, com banheiros, acesso à merenda e área de lazer. Funciona nos três turnos e oferece Educação Infantil e Ensino Fundamental das séries iniciais, com regime seriado, e conta com um total de 486 alunos indígenas.

A extensão possui nove salas de aula em alvenaria, uma sala para professores e coordenadores, uma cozinha, banheiros com sanitários e lavatório separados por sexo, um bebedouro com duas torneiras, uma ampla área de lazer, com gramado e um campo de futebol para prática de Educação Física. As salas de aula contam com mesas e cadeiras individuais, suficientes para todos os alunos e mesas para os professores.

As paredes internas e externas estão desgastadas, há boa ventilação e iluminação, tanto artificial como natural.

O quadro de docentes é composto por 20 professores, sendo 17 indígenas e três não índios e quatro coordenadores, sendo três indígenas e apenas um não índio. Esses coordenadores atendem às demais extensões: Afonso Pena, Antonio Maria e Dr. Nelson de Araújo.

\subsubsection{Extensão Afonso Pena}

Essa extensão atende alunos indígenas e está localizada a três quilômetros da sede, escola Porto Lindo. Seus alunos pertencem às séries iniciais do Ensino Fundamental, com regime multisseriado, sendo turno matutino reservado às $3^{\mathrm{a}}$ e $4^{\mathrm{a}}$ séries, e o vespertino, às $1^{\mathrm{a}}$ e $2^{\mathrm{a}}$ séries, perfazendo um total de 58 alunos indígenas.

A escola possui uma sala de aula em alvenaria e outra em madeira. Não possui banheiro, apenas um mictório do outro lado da rua, e não há bebedouro, apenas água em torneiras. Possui uma área de lazer com gramado e um campo de futebol de chão batido, para as aulas de Educação Física. Na escola trabalham quatro professores - três indígenas e um não índio - contratados em regime temporário.

\subsubsection{Extensão Antonio Maria Coelho}

Essa Unidade Escolar atende alunos indígenas e está localizada a cinco quilômetros da sede da Reserva Porto Lindo. A escola oferece as séries iniciais de Ensino fundamental em regime multisseriado, sendo as $1^{\mathrm{a}}$ e $2^{\mathrm{a}}$ séries no turno matutino e, no turno vespertino, as $3^{\mathrm{a}}$ e $4^{\mathrm{a}}$ séries, somando um total de 82 alunos. 
A unidade escolar possui três salas aula de madeira, uma cozinha e apenas um mictório, usado por ambos os sexos. Nela não há bebedouro, água apenas em torneiras. O mobiliário da sala de aula são mesas e cadeiras individuais.

Os docentes que ministram aula na extensão são contratados (contrato temporário), exceto a professora Lídia, não índia, que é funcionária efetiva de Mundo Novo, MS, e está emprestada à instituição há 22 anos, por pedido dos próprios indígenas, pois fala bem a língua guarani, com os quais tem bom relacionamento, como ela mesma afirmou em sua entrevista.

O quadro curricular do ensino fundamental da Escola Polo Municipal de Educação Infantil e Ensino Fundamental José de Alencar prevê carga horária de 200 dias letivos, com quatro aulas de 50 minutos, nos turnos matutino e vespertino.

No ano de 2007, foi realizado o segundo concurso público no município de Japorã, para suprir a falta de funcionários efetivos, com isso o quadro de professores efetivos aumentou na Escola Municipal Polo José de Alencar e suas Extensões. Nesse recorte histórico, a questão da estrutura física ainda é a mesma de 2005, precária, e número de alunos sempre aumentando.

Em 2009, foi realizado o terceiro concurso público nesse município, agora com um diferencial significativo, pois é reservada cota de vagas à comunidade indígena, para professores que iriam ministrar aulas dentro da reserva nas Extensões da Escola Polo José de Alencar para os anos iniciais do ensino fundamental, tendo como pré-requisito a Língua Guarani.

A comunidade Nandeva - Guarani vem, desde 2005, reivindicando uma Escola Indígena, com gestores indígenas, com material didático diferenciado, o uso da língua materna como parte do currículo. A partir do concurso de 2009, a comunidade começou a ter força para criar o projeto da Escola Indígena dentro da reserva Porto Lindo.

Assim, em 2013, a escola finalmente recebeu a autorização e credenciamento de acordo com a deliberação do CEE/MS n 10.189 de 31/10/2013; nesse momento, a Escola Extensão Porto Lindo desvinculou-se da Escola Polo José de Alencar e passou a se chamar Escola Municipal Indígena Educação Infantil e Ensino Fundamental MBO'EHA TEKORA Guarani Polo. Assim, as unidades escolares dentro da reserva passaram a funcionar como uma extensão da unidade acima citada passando a chamar: (I) Escola Municipal Indígena de Educação Infantil Ensino Fundamental Extensão Dr. Nelson de Araujo (Extensão Dr. Nelson Araujo - Missão), (II) Escola Municipal Indígena de Educação Infantil e Ensino Fundamental Extensão MBO'EHAO ARANDU PORÃ (Extensão Antonio Maria Coelho) e (III) Escola Municipal 
Indígena de Educação Infantil e Ensino Fundamental Extensão MBO'EHAO MARANGATU PORÃ (Extensão Afonso Pena).

Uma vez reconhecidas as Escolas da Reserva Porto Lindo oficialmente como Escolas Indígenas, a questão do investimento melhorou; o dinheiro agora é destinado à Escola Indígena e, com essa valorização, foi possível reformar a Escola Pólo e construir prédios novos para as Extensões, com exceção da escola que ainda requer reforma, a Dr. Nelson de Araujo.

Enquanto o processo da escola estava em tramitação - que foram aproximadamente oito anos - os professores indígenas que não tinham formação em nível superior buscaram aperfeiçoamento, contudo ainda existem algumas áreas em que não há professores indígenas com formação específica, mas a comunidade está procurando suprir essa necessidade e no momento conta a colaboração de professores não índios.

\subsection{A escola ontem}

Neste tópico, será traçada uma viagem ao passado da educação escolar na comunidade indígena, na busca por verificar como aconteceu a educação escolar do não índio, pois eles ainda não possuem a educação diferenciada, prevista em legislação. Por outro lado, a escola que os índios da Reserva Porto Lindo possuem é uma escola pensada, até pouco tempo atrás, coordenada e ativada por não índios.

A história da educação escolar indígena na Reserva Porto Lindo teve início quando o município de Japorã ainda era Distrito de Iguatemi, que, anos depois, passou a ser Distrito de Mundo Novo, tornando-se município autônomo em 1992. Pelos documentos encontrados, o sistema escolar no município iniciou-se entre 1960 e 1970 e, na época, existiam escolas municipais e escolas estaduais consideradas escolas rurais.

Praticamente iguais com relação à estrutura física e documentos, as escolas apresentavam duas salas de aula, uma cozinha, uma área de lazer coberta, um sanitário isolado, um poço para abastecimento de água e uma caixa da água para reservatório de água. As salas eram multisseriadas, atendendo de primeira a quarta séries.

O início do processo de escolarização entre o povo guarani deu-se com a fundação da Missão Caiuá, em 1928, na área Indígena de Dourados. Essa Missão era ligada à Igreja Presbiteriana Americana, e a escola chegava à Reserva Porto Lindo em 1960, quando foi instalada próxima da Reserva indígena. O reverendo Rubens descreve, com clareza, como se deu esse início: 
Registrando a história da educação escolar da Comunidade Indígena Ñandeva-Guarani da Reserva Porto Lindo no município de Japorã, MS

Por volta de 63 ou começo de 64 , nós começamos então a escola indígena na Missão, curiosamente considerando aquela situação no momento, nós começamos a escola do nada; o primeiro quadro de giz foi um tambor de duzentos litros, que nós pintamos de verde. E nós escrevíamos as primeiras letras e palavras para as crianças começarem a ter noção das primeiras letras e, depois, nós fizemos um barracão rústico que ficava bem na beira da picada que fazia divisa entre a localidade da Missão e a própria Reserva. Um barracão bem rústico, com parede de taquara, coberto com tabuinha, e ali nós começamos a primeira escolinha e colocamos um quadro de giz e nós trabalhávamos então, eu assumi esta parte da educação e enquanto o Rev. Troques e sua esposa ficou com a parte do ambulatório médico [sic]. (Reverendo Rubens Carneiro, Entrevista, 2006).

A Missão Evangélica Caiuá iniciou o trabalho de educação com recursos próprios e, em 06 de setembro de 1982, através da lei municipal n. 091/82, firmou convênio com a Prefeitura Municipal de Mundo Novo. Assim, a escola situada na estrada que liga Mundo Novo a Jacareí, próxima à Reserva Indígena Porto Lindo, passou a oferecer 120 vagas para a $1^{\mathrm{a}}$ e $2^{\mathrm{a}}$ séries, em dois turnos - matutino e vespertino - e em sala multisseriada, com professores leigos. A Missão Caiuá tornou-se, então, responsabilidade da Secretaria Municipal de Educação e Cultura de Mundo Novo, e a escola recebeu o nome de "Dr. Nelson de Araújo".

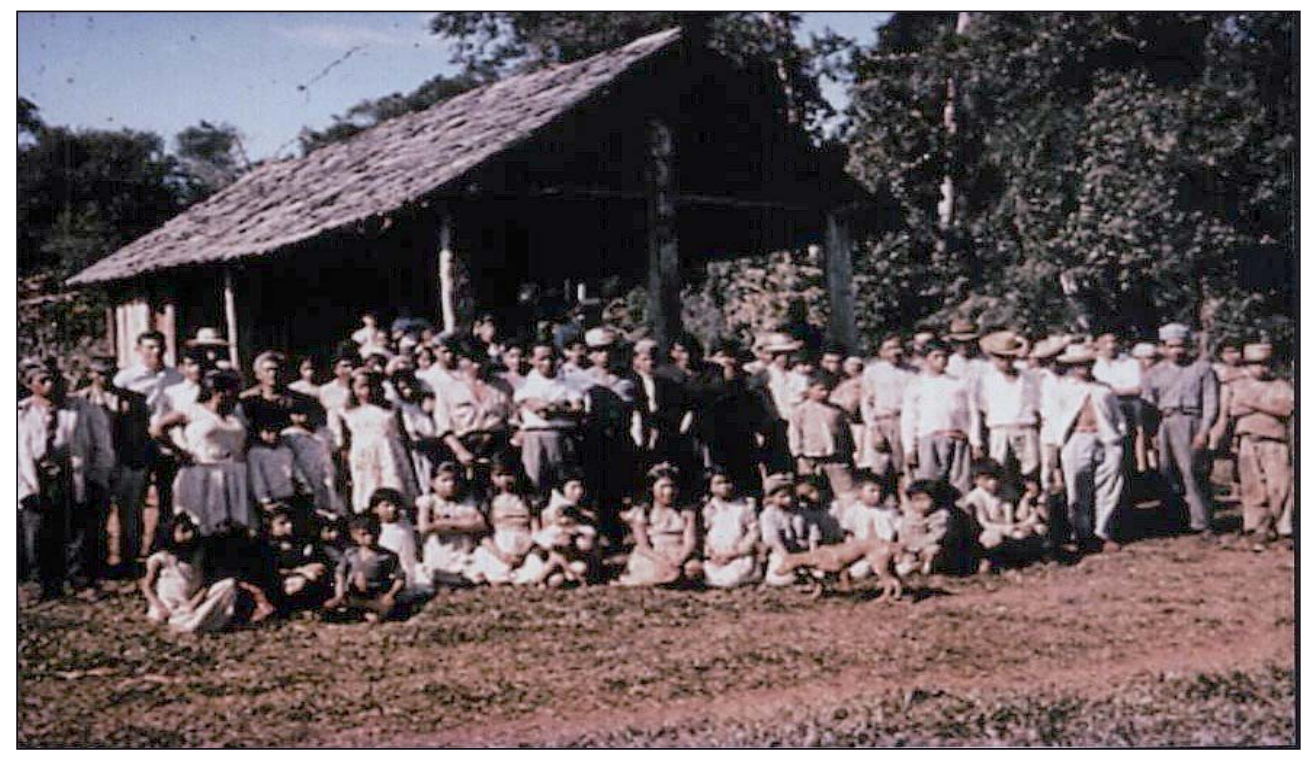

Figura 2 - A primeira escola da missão Caiuá, na reserva Porto Lindo.

Fonte: Arquivo pessoal do Reverendo Rubens Francisco Carneiro, 2005. 
A escola funcionou, por longo tempo, sem autorização do Conselho Estadual de Educação, por causa da irregularidade na documentação dos alunos que ali estudaram, na sua maioria indígena, cujos documentos dependiam da atuação da Fundação Nacional do Índio (FUNAI), sediada em Campo Grande. Alguns desses documentos haviam sido extraviados e só foram recuperados em 1984, propiciando, então, a autorização e validação para funcionamento da escola.

A educação sistematizada na Reserva Porto Lindo iniciou em 1960, com 30 alunos, como uma escola independente. Com o passar dos anos, as modificações foram ocorrendo tanto na escola como em toda a comunidade.

\section{CONHECER PARA QUESTIONAR}

“A escola para os índios é a instituição mais antiga no país e, desde o período colonial vem adequando-se aos diferentes contextos produzidos pelos grupos sociais na sua relação com o estado" (BERGAMSCHI, 2004, p. 114). No período colonial, a escola foi vista como um instrumento de domesticação através da catequese realizada por ações educativas.

Essas ações educativas iniciadas pelos jesuítas vêm perpassando todos os momentos históricos da escola, com influências até o momento atual. No entanto a educação escolar para os indígenas na Reserva Porto Lindo iniciada na década de 60, ocorreu em um ambiente semelhante ao período colonial, agora sem os jesuítas; os responsáveis pela implementação do processo de escolarização foram os missionários presbiterianos que vieram com o intuito de evangelizar os indígenas.

A Missão Caiuá pretendia levar ao indígena o conhecimento da palavra de Deus, o conhecimento do evangelho, para isso a missão sempre usou o que chamamos de tripé "educação, saúde e evangelização"; a missão existe para isto, e então nós fomos lá, trabalhamos e foi um trabalho muito bom; por anos seguidos, a gente realizou este trabalho [sic]. (Reverendo Rubens Carneiro, entrevista, 2006).

Os missionários chegaram à Reserva Porto Lindo pela primeira vez em 1961, com o objetivo de conhecer o território e a clientela que pretendiam conquistar para sua obra de evangelização. 


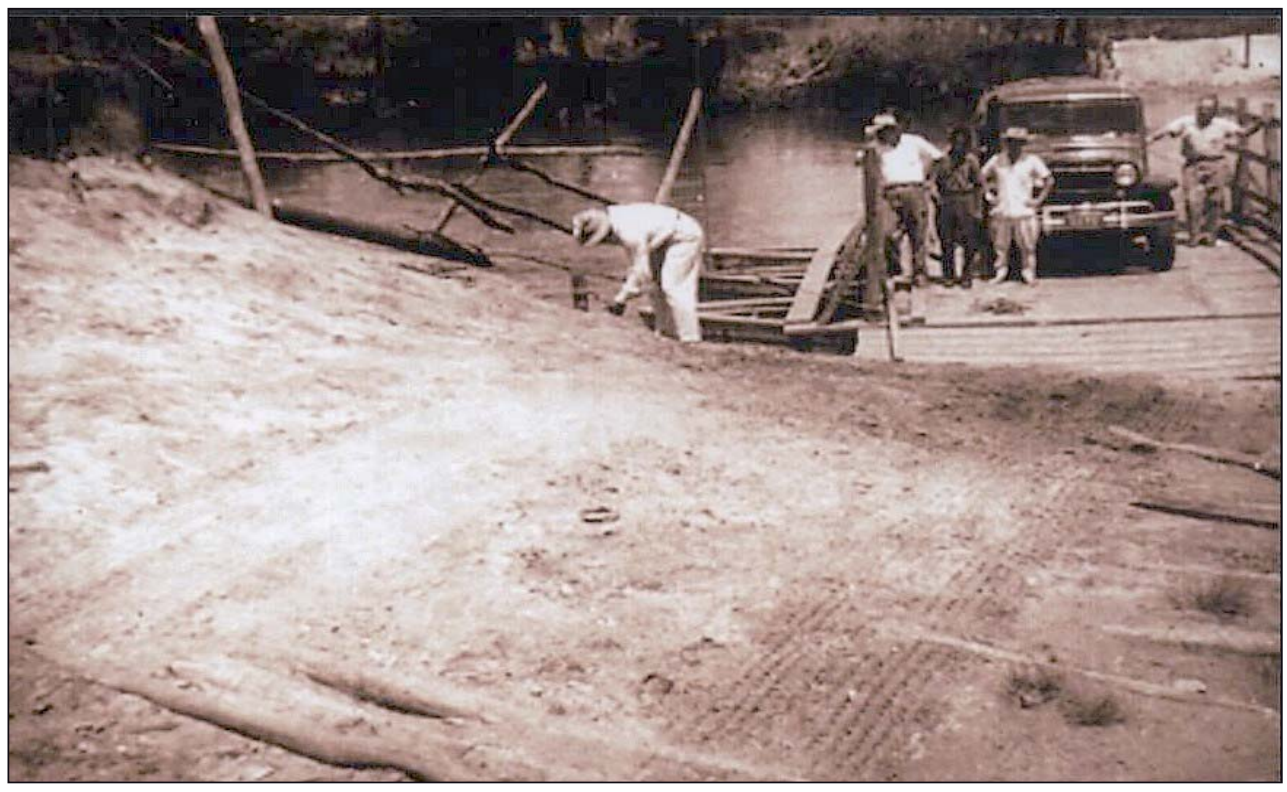

Figura 3 - Os missionários chegando à reserva Porto Lindo.

Fonte: Arquivo pessoal de Reverendo Rubens Francisco Carneiro, 2005.

O Revendo Rubens, assim como o professor Valdomiro, que na época era aluno dessa escola, narraram que a escola da Missão iniciou seu trabalho utilizando como metodologia a língua guarani e somente depois que os alunos adquiriam domínio da leitura e da escrita em guarani é que passavam a ensinar o português, uma vez que acreditavam ser essa a metodologia mais facilitadora para a aprendizagem do aluno. A escola possuía um conjunto de oito cartilhas em guarani que eram utilizadas nas aulas como material de apoio.

Na verdade, em outro tempo, a questão religiosa se mantém como justificativa para envolver os indígenas. Acompanhando os avanços científicos, apenas um elemento pode ser considerado novo nessa proposta: a preocupação com o atendimento à saúde, elemento inexplorado na atuação jesuítica do período colonial.

A missão Caiuá tem o objetivo de evangelizar e, para tanto, utilizou a educação escolar para alcançar o sucesso esperado. Hoje, possui missionários indígenas, e muitos membros da comunidade religiosa são indígenas. E então surge a pergunta: os missionários saíram de São Paulo para atuarem entre os indígenas com caráter salvacionista?

A escola da Missão Caiuá foi a primeira escola da região a atender os indígenas e também foi a primeira escola, entre os indígenas e não índios, a ter uma professora normalista, segundo o reverendo Rubens. 
Esse fato nos chama a atenção e nos faz questionar o destaque dado à presença de uma professora formada. Isto aponta para o fato de que todos os outros eram professores leigos e, portanto, na região, na década de 1960, qualquer pessoa podia ser professor? Se qualquer pessoa podia ser professor, qual seria o objetivo central da escola: instruir ou evangelizar?

O professor Valdomiro vem colaborar com a seguinte informação:

Quando a gente começou a estudar, e quando era pequeno, eu estudei ali na Missão e, na época, a Missão tinha uma educação assim um pou$\mathrm{co}$, é, eu diria tradicional, porque onde o aluno tinha que aprender. $\mathrm{Na}$ cabeça dos professores da época, tinha que aprender de um jeito ou do outro, tinha que saber ler e escrever, mas eu lembro que, na época, uma das coisas que foi importante, do pessoal da Missão, é que tinha livros escritos em guarani. Então, facilitou a leitura dos alunos indígenas [...] na época, o pessoal falava cartilha, não era livro, então tinha número um dois, três, quatro, cinco, seis, sete e oito se não me engano, e então você conseguindo até a cartilha de número oito e dando conta de ler os oito livros escritos em guarani, você já poderia estar começando estudar na língua portuguesa. E então foi assim que comecei a ler e escrever junto com o povo da Missão [sic]. (Prof. Valdomiro Ortiz, entrevista, 2006).

O ensinar na língua guarani vem perpassando todo o período da história da educação escolar para os indígenas. Entre eles, os conflitos são constantes, e os pais querem que seus filhos estudem com professores não índios, pois entendem que as crianças escolarizadas precisam desses conhecimentos para fazer parte da comunidade do não índio, mas, ao mesmo tempo temem que seus filhos se afastem de sua cultura.

Podemos perceber nas falas dos entrevistados que os conflitos com o uso da língua guarani vem de longa data. $O$ distanciamento entre a linguagem coloquial, em guarani, e a linguagem escolar, em português, pode indicar uma questão interessante que será discutida um pouco mais adiante: as funções educativas diferenciadas entre família e a comunidade e a escola. A percepção, ou a expectativa, de que, por meio da educação escolar, o indígena passe a ter um espaço na sociedade não indígena, pode ser percebida pela professora Lídia, ao relatar que, quando começou a trabalhar na escola da Reserva, em 1985, os pais preferiam que os alunos aprendessem em português.

O conflito em ensinar ou não a/na língua guarani está presente até os dias atuais. Alguns pais preferem que seus filhos estudem na escola fora da Reserva, com professores não índios. O professor Venâncio nos relata que essa realidade vem sofrendo algumas mudanças, pois os professores indígenas estão realizando reuniões e explicando aos pais a importância da língua materna na escola e na vida da comunidade. Explicam ainda a importância do registro, ou seja, a escrita, pois muitos dos indígenas sabem falar a língua 
guarani, mas não sabem escrever e, na sociedade atual, a escrita é algo fundamental. O prof. Venâncio diz que, se não aprenderem a língua guarani na escola, "vão escrever tudo errado e que na cabeça dos pais só a oralidade basta [sic]".

A educação, para os indígenas, tem um papel bem mais amplo, e a escola seria só mais um local para se adquirir instrução. Quando de seu surgimento, a escola ocidental tem esse papel de instruir, ela é responsável por aqueles conjuntos de saberes específicos. Hoje em dia, com a omissão dos grupos familiares e sociais na tarefa educativa, a escola acaba sendo responsável por toda a educação.

Será que os indígenas não estão percorrendo um percurso próprio deles, de constituição de escola indígena com outra característica que não seja ocidental? Haverá ainda espaço para construção de uma escola com características e identidade particular no momento em que estão "subordinados" aos referenciais curriculares nacionais para as escolas indígenas, associados a um conjunto de normatizações?

Pode ser que os indígenas estejam querendo percorrer um caminho de construção de escola indígena, assim como o mundo ocidental construiu uma identidade de escola a partir do século XVI, no seu início, guardadas as proporções de tempo e contexto. Essa busca agora é dificultada pela regulamentação e tutela do Estado, em relação a essa escola e o seu funcionamento, criando empecilhos para que eles possam percorrer um caminho próprio.

A escola ajuda a resgatar a cultura, a língua, porque, na verdade, a gente fala tudo misturado, a gente fala espanhol, fala um pouco de guarani e até palavra em português tem no meio; então, está tudo misturado, na nossa educação aqui, na aula de guarani a gente procura ensinar a língua que era antiga mesmo, para resgatar é muito importante ter aula de guarani para nós, apesar de que, agora os mais antigos já estão desaparecendo então cada dia que passa estamos perdendo aquele antigo que tem a língua própria [sic]. (Prof. Venâncio Cáceres, entrevista, 2006).

Algumas expectativas são pertinentes, tal como a do registro escrito da história de sua comunidade; outras são improváveis, tal como, por exemplo, a de que a escola vai ajudar a resgatar os rezadores. Como a escola vai ajudar a preservar suas tradições e artesanatos? Isto implicaria uma transformação violenta no currículo escolar e, até que ponto, essa transformação é possível?

É no processo de escolarização formal que a escrita passa a ser difundida entre as sociedades indígenas. A escrita, que até pouco tempo não era utilizada pelo índio, parece ser de fundamental importância, na visão dos indígenas. Como já foi mencionado pelo professor Venâncio, os pais ainda têm muita dificuldade em aceitar a língua guarani na escola, acreditando 
que precisam mais do português, pois o guarani eles já sabem. Mas, como lembra o professor Venâncio, sabem falar, mas não sabem escrever em guarani e, mais tarde, quando quiserem trabalhar dentro da Reserva, não estarão habilitados.

Como já foi mencionado, por volta dos anos 90, os indígenas da Reserva Porto Lindo iniciaram o curso de capacitação para professores, através do projeto Ara Verá, uma luta de muitos anos das comunidades indígenas com lideranças não indígenas para que os membros das comunidades assumissem a educação escolar dentro das Reservas.

Muitos dos professores estão se capacitando, tanto em nível médio como em nível superior, pois eles reivindicam uma escola indígena e não uma escola para índio, mas isto não quer dizer que estejam recusando os conhecimentos ocidentais e sua importância na vida da comunidade, segundo o professor Venâncio.

A educação escolar indígena é algo desejado pelos Ñandeva-Guarani. Os professores entrevistados e as conversas informais demonstram o interesse e as expectativas que eles depositam na educação escolar.

Neste momento histórico, talvez o primeiro passo para a busca da escola indígena seja separação entre as diretrizes aplicáveis à escola do não índio e as relativas à escola indígena, para que os índios possam planejar e estruturar a escola de acordo com seus princípios, escolhendo as pessoas que nela vão trabalhar segundo critérios que levem em conta o conhecimento dos assuntos da comunidade, ou seja, os professores devem ser oriundos da comunidade indígena e, ainda, que disciplinas como português e matemática, entre outras - segundo o professor Venâncio, as mais difíceis e para as quais ainda não existem pessoas formadas - possam ser ministradas por não índios até que, como é crença entre eles, os próprios indígenas possam assumir as disciplinas referentes a todas as áreas do conhecimento ocidental. E então como será essa escola diferenciada?

Pode-se, então, constatar que, no depoimento do professor Venâncio, a escola diferenciada ainda não tem um projeto, é algo sonhado, mas a prática gera muitos questionamentos porque essa escola, mesmo se tornando uma escola indígena, está sob a tutela do estado e da legislação estadual. Então, até que ponto esta escola seria diferenciada? E o material didático? Será que a comunidade indígena conseguiria produzir o seu próprio material voltado à sua realidade? Essa escola será uma escola diferenciada ou apenas uma escola indígena? Pois, como o professor Valdomiro já afirmou, o aluno precisa estudar através de sua realidade. E, se assim for, é fundamental destacar que os professores que atuam nas extensões sejam frutos da escola tradicional. 
Um dos problemas mais relevantes é o financeiro; há informações que indicam que muitos abandonam a escola por não terem roupas ou calçados adequados, passando a trabalhar para conseguir adquirir bens de consumo, de forma muito semelhante ao que ocorre na educação escolar do não índio, que também sofre com a evasão escolar pelo mesmo motivo. Então, no que a educação diferenciada estaria ajudando o aluno indígena?

Diante dos problemas apresentados, a comunidade indígena está preocupada com o futuro de seus filhos e deseja que eles prosperem, estão sempre buscando auxílio para poderem amenizar os problemas enfrentados por todos os membros da comunidade indígena Nandeva-Guarani.

O que os Nandeva-Guarani apontam como deficitário são as mesmas reivindicações da escola do não índio e, então, surgem mais estas perguntas: o que há de particular na educação indígena? Como essa escola diferenciada vai ajudar a resgatar sua cultura, sua história e suas crenças para que a escola não seja "instrumento de imposição de valores?" Os indígenas têm o direito, e é importante a regulamentação dessa escola indígena; essa escola diferenciada representa um momento interessante do processo, mas a regulamentação, por si só, não garante uma escola diferenciada.

\section{IMPOSSÍVEL UMA CONCLUSÃO...}

O processo de implantação da escola começa com a intenção de evangelização, e a escola entra "de carona" nesse objetivo. Se pensarmos nos objetivos e funções que a escola está desempenhando, podemos nos perguntar quantas práticas estão sendo efetivadas com outros objetivos que não a educação indígena? Mas se pensarmos nas suas possibilidades, o percurso histórico mostra alguns avanços em relação a seu início, tais como a ampliação do número de escolas e de crianças atendidas.

Esse processo inicia-se tímido, com alguns poucos alunos na escola da Missão, como é conhecida por todos, e hoje a Escola Polo Municipal de Educação Infantil, Ensino Fundamental José de Alencar e suas extensões atendem mais de 1700 alunos, sendo que $60 \%$ de sua clientela são indígenas.

Nesses 43 anos de educação para os índios, muitos frutos foram colhidos, pois hoje a comunidade escolar conta com vários professores indígenas com habilitações específicas como Normal em Nível Médio ${ }^{11}$ e

\footnotetext{
${ }^{11}$ Projeto Ara Verá.
} 
outros cursando o nível superior. Mas as expectativas ainda são intensas, com a busca de uma educação escolar indígena gerenciada pelos membros da comunidade, baseados na alegação de que só assim vão conseguir uma educação diferenciada.

No entanto existe um dilema a respeito de qual língua deve ser utilizada no processo de ensino e de quais os conteúdos devem ser ministrados, pois, como foi dito nos depoimentos, os indígenas querem cursar um ensino superior e, para isto, existem conteúdos da base nacional comum que não podem ser esquecidos.

A questão em torno da educação diferenciada ainda não está bem clara: o processo de escolarização se iniciaria de forma diferenciada, mas o fim seria compatível com a educação do não índio?

A comunidade escolar indígena almeja uma educação diferenciada, mas em momento algum nega a necessidade dos conhecimentos ocidentais, pois se considera "integrada" à sociedade brasileira. Se os indígenas sentem-se integrados à sociedade brasileira, e, efetivamente, não possuem grande visibilidade enquanto grupo, pode-se perguntar se, muitas vezes, não somos nós, os não índios, que os tornamos invisíveis? Partindo do pressuposto de que o estado de Mato Grosso do Sul possui a segunda maior população indígena, poder-se-ia supor que os não índios tivessem um maior esclarecimento a respeito desse povo e sua cultura, mas não é isso que acontece. Os não índios, muitas vezes, aprendem na escola que índio caça, pesca e mora em uma oca - e a escola que deveria, ou poderia, ser um espaço de reflexão e construção de uma sociedade sem preconceitos, passa a ser geradora de formas de preconceitos e discriminações.

Como foi constatado nos depoimentos, a verdadeira educação para os indígenas só pode ser adquirida no cotidiano da vida, no seio familiar e na comunidade em que vivem, marcada que é, pelo seu processo histórico, social e cultural como um todo. Apenas nesse sentido entendem o viver em harmonia e a aprendizagem significativa para cada indivíduo e para a comunidade como um todo.

\section{REFERÊNCIAS}

ABBUD, Maria Luiza Macedo. Formação contínua de professores na "escola reflexiva" da PUC-SP: seus protagonistas revivem esta prática. Tese (Doutorado em Educação) Universidade Estadual Paulista Júlio de Mesquita Filho, Marília, SP, 2003. 
Registrando a história da educação escolar da Comunidade Indígena Ñandeva-Guarani da Reserva Porto Lindo no município de Japorã, MS

BERGAMASCHI, Maria Aparecida. Por que querem e por que não querem escola os Guarani? Tellus, Campo Grande, ano 4, n. 7, p. 105-120, out. 2004.

BRAND, Antonio. O impacto da perda da terra sobre a tradição Kaiowá/Guarani: os difíceis caminhos da palavra. 1997. Tese (Doutorado em História) - Pontifícia Universidade Católica do Rio Grande do Sul, Porto Alegre, RS, 1997.

BRAND, Antonio. Programa Kaiowá/Guarani/UCDB. In: REUNIÃO DE ANTROPOLOGIA DO MERCOSUL: antropologia em perspectivas, 5., 2003, Florianópolis. Anais... Florianópolis: UFSC, 2003.

BRANDÃO, Carlos Rodrigues. O que é educação. 43. ed. São Paulo: Brasiliense, 2004.

INSTITUTO BRASILEIRO DE GEOGRAFIA E ESTATÍSTICA (IBGE), 2010. Disponível em: <www.ibge.gov.br/catálogos/indicadores>. Acesso em: 14 out. 2016.

CARVALHO, Ieda Marques de. O CIMI e sua assessoria aos movimentos indígenas. Tellus, Campo Grande, ano 2, n. 2, p. 137-151, abr. 2002.

FLEURI, Reinaldo Matias; BITENCOURT, Silvana Maria; SCHUCMAN, Lia Vainer. A questão da diferença na educação: para além da diversidade. In: REUNIÃO ANUAL DA ANPED, 25., 2002, Caxambú. Anais... Caxambú: ANPED, 2002. Disponível em: <http://www.anped.org.br/25/sessoesespeciais/reinaldofleuri.doc>. Acesso em: 27 jan. 2007.

LANDA, Beatriz dos Santos. Os Nandeva/Guarani e o uso do espaço na terra indígena Porto Lindo/Jacarey, Município de Japorã/MS. 2005. Tese (Doutorado em História) - Pontifícia Universidade Católica do Rio Grande do Sul (PUC-RS), Porto Alegre, RS.

MAGALHÃES, Justino Pereira. Breve apontamento para a história das instituições educativas. In: LOMBARDI, J. C. História da educação: perspectivas para um intercâmbio internacional. Campinas: Autores Associados/HISTEBR, 1999.

MARTINS, Gilson Rodolfo. Breve Painel Etno-Histórico de Mato Grosso do Sul. 2. ed. Campo Grande: UFMS, 2002.

MEIHY, José Carlos Sebe Bom. Manual de história oral. São Paulo: Loyola, 1996.

NASCIMENTO, Adir Casaro. Escola indígena: palco das diferenças. Campo Grande: UCDB, 2004.

ROSSATO, Verônica Lovato. Normal em nível médio - formação de professores Guarani/Kaiowá - Projeto Ara Verá.. Campo Grande: Secretaria de Estado de Educação/ MS, 1999.

SILVA, Marcio Ferreira da; AZEVEDO, Marta Maria. Pensando as escolas dos povos indígenas no Brasil: o movimento dos professores indígenas do Amazonas, Roraima e Acre. In: SILVA, Aracy da; GRUPONI, Benzi; DONIZETE, Luis (Org.). A temática indígena na escola: novos subsídios para professores de $1^{\circ}$ e $2^{\circ}$ graus. 4 . ed. São Paulo: Global: 2004. 
VIETTA, Katya. “Bom pastor dá conselho bom”: Missões evangélicas e igrejas neopentecostais entre os Kaiowá e os Guarani em Mato Grosso do Sul. Tellus, Campo Grande, ano 3, n. 4, p. 109-135, abr. 2003.

\section{ENTREVISTAS}

BENEDITO TROQUES. Nascido em 01/03/1931. Reverendo da Igreja Presbiteriana na Missão Caiuá. Entrevista realizada pela pesquisadora Cristiane Beatriz Dahmer Couto na Cidade de Dourados, MS, gravada em fita cassete e transcrita para texto digital, com documento de cessão de direto de uso devidamente assinado no dia 28/12/2006.

LÍDIA ROCHA JAVOLSKI. Nascida em 22/12/1952. Professor da Escola Pólo José de Alencar - Extensão Porto Lindo. Entrevista realizada pela pesquisadora Cristiane Beatriz Dahmer Couto na Aldeia Porto Lindo no Município de Japorã, MS, gravada em fita cassete e transcrita para texto digital, com documento de cessão de direto de uso devidamente assinado no dia 23/11/2006.

PAULO FRANJOTE. Nascido em 17/06/1970. Secretário de Educação do Município de Japorã , MS. Entrevista realizada pela pesquisadora Cristiane Beatriz Dahmer Couto gravada em fita cassete e transcrita para texto digital, com documento de cessão de direto de uso devidamente assinado no dia 05/12/2006.

VALDOMIRO ORTIZ. Nascido em 18/01/1972. Professor indígena da Escola Pólo José de Alencar - Extensão Porto Lindo. Entrevista realizada pela pesquisadora Cristiane Beatriz Dahmer Couto na Aldeia Porto Lindo no Município de Japorã, MS, gravada em fita cassete e transcrita para texto digital, com documento de cessão de direto de uso devidamente assinado no dia 25/11/2006.

VENÂNCIO CÁCERES. Nascido em 15/05/1972. Professor indígena da Escola Pólo José de Alencar - Extensão Porto Lindo. Entrevista realizada pela Pesquisadora Cristiane Beatriz Dahmer Couto na Aldeia Porto Lindo no Município de Japorã, MS, gravada em fita cassete e transcrita para texto digital, com documento de cessão de direto de uso devidamente assinado no dia 20/11/2006.

RUBENS FRANCISCO CARNEIRO, Nascido em 24/03/1940. Reverendo da Igreja Presbiteriana na Missão Caiuá. Entrevista realizada pela pesquisadora Cristiane Beatriz Dahmer Couto na Cidade de Dourados, MS, gravada em fita cassete e transcrita para texto digital, com documento de cessão de direto de uso devidamente assinado no dia 28/12/2006. 